This item was submitted to Loughborough's Research Repository by the author.

Items in Figshare are protected by copyright, with all rights reserved, unless otherwise indicated.

\title{
Impacts of talent development environments on athlete burnout: a self- determination perspective
}

PLEASE CITE THE PUBLISHED VERSION

http://dx.doi.org/10.1080/02640414.2016.1240370

\section{PUBLISHER}

(c) Taylor \& Francis

\section{VERSION}

AM (Accepted Manuscript)

\section{PUBLISHER STATEMENT}

This work is made available according to the conditions of the Creative Commons Attribution-NonCommercialNoDerivatives 4.0 International (CC BY-NC-ND 4.0) licence. Full details of this licence are available at: https://creativecommons.org/licenses/by-nc-nd/4.0/

\section{LICENCE}

CC BY-NC-ND 4.0

\section{REPOSITORY RECORD}

Li, Chunxiao, C.K. John Wang, and Do Young Pyun. 2016. "Impacts of Talent Development Environments on Athlete Burnout: A Self-determination Perspective”. Loughborough University.

https://hdl.handle.net/2134/22717. 
Impacts of Talent Development Environments on Athlete Burnout: A Self-

Determination Perspective

Chunxiao Li

The Education University of Hong Kong

Chee Keng John Wang

Nanyang Technological University

Do Young Pyun

Loughborough University

Author Note

Chunxiao Li is with the Department of Health and Physical Education, The

13 Education University of Hong Kong. Chee Keng John Wang is with the Physical

14 Education and Sports Science Academic Group, National Institute of Education,

15 Nanyang Technological University. Do Young Pyun is with the School of

16 Sport, Exercise and Health Sciences, Loughborough University.

17 We would like to thank all our helpers and participants.

18 We declare that there are no conflicts of interest in this study.

19 Correspondence concerning this manuscript should address Dr. Chunxiao Li,

20 Department of Health and Physical Education, The Education University of Hong

21 Kong, Hong Kong, China Tel: +852 2948 8913, E-mail: cxli@ied.edu.hk

22 Word count: 4,199

25 Keywords: expertise, talent development, needs satisfaction, burnout, athlete 
1 Abstract

2 Guided by Deci and Ryan’s (2000) self-determination theory, this survey study

3 aimed to examine the effects of the talent development environmental factors on

4 athlete burnout. Talented adolescent athletes $(N=691)$ filled out a survey form

5 measuring the talent development environmental factors, needs satisfaction, and

6 burnout. The findings showed that three talent environmental factors (i.e., long-term

7 development focus, holistic quality preparation, and communication) were negative

8 predictors of burnout via needs satisfaction. It was concluded that the three talent

9 development environmental factors may be important for facilitating athletes' needs

10 satisfaction and preventing burnout. 
Impact of Talent Development Environment on Athlete Burnout: A Self-

3 To achieve sporting excellence, many sports organisations or associations have

4 invested considerable resources or efforts to develop athletic talents (Baker \&

5 Schorer, 2010; Collins \& MacNamara, 2012). Talent development is about providing

6 the most conducive learning environment to realize athletes’ potential in sports

7 (Williams \& Reilly, 2000). It is a long-term journey for athletes to develop

8 themselves into an excellent performer (Ericsson, 2007). Talented athletes are

9 required to combat numerous challenges such as injury, repetitive training, and

10 parental pressure alongside this long-term journey (Gustafsson, Kenttä, \& Hassmén,

11 2011). Unfortunately, some athletes may fail to meet these challenges and suffer

12 from burnout. Burnout is a maladaptive psychological syndrome, manifesting as

13 reduced sense of accomplishment, physical and emotional exhaustion, and sport

14 devaluation (Raedeke, 1997). Burnout can negatively affect athletes' health and sport

15 performance (Gustafsson et al., 2011; Schaufeli \& Bunnk, 2003). It is therefore

16 necessary to understand the antecedents of athlete burnout. Recently, several studies

17 have applied self-determination theory (SDT; Deci \& Ryan, 2000) for examining

18 athlete burnout (Gustafsson, Hancock, \& Côté, 2014; Li, Wang, Pyun, 2013).

19 Drawing on SDT, this research aims to understand how athlete burnout is related to

20 the social context (i.e., talent development environment).

\section{Talent development environment}

22 The talent development environment refers to the all aspects of the surroundings,

23 where athletic potentials are realised (Henriksen, Stambulova, \& Roessler, 2010;

24 Martindale, Collins, \& Daubney, 2005). It is evident that talent development

25 environmental factors (e.g., training programme, parents) influence athletes’ expert 
1 performance (Araújo \& Davids, 2011; Henriksen, Larsen, \& Christensen, 2014; Li,

2 Wang, \& Pyun, 2014). Talented athletes are required to overcome environmental

3 constraints or adapt external factors such as setbacks and arduous training

4 programmes to acquire their sport expertise (Phillips, Davis, Renshaw, \& Portus,

5 2010). This implies a need to identify significant environmental factors for effective

6 talent development. Several key features of effective and controllable talent

7 development environment were identified in review studies (for reviews, see Li et al.,

8 2014; Martindale et al., 2005). In particular, five key and effective environmental

9 factors have consistently emerged from the talent development literature and are

10 believed to influence talent development, including long-term development focus

11 (e.g., ongoing opportunities, de-emphasis of winning), holistic quality preparation

12 (e.g., clear training guidance, balanced training and life), support network (e.g., sport

13 science support, coach support), communication (e.g., feedback, rationale for

14 training), and alignment of expectations (e.g., goal setting and review; Li, Wang,

15 Pyun, \& Martindale, 2015). According to SDT (Ryan \& Deci, 2000), the five

16 environmental factors are hypothesised to influence talented athletes' three basic

17 psychological needs. However, little empirical evidence is available concerning how

18 these effective environmental factors are related to the three basic psychological

19 needs.

\section{Environment and basic psychological needs}

21 The three basic psychological needs are autonomy (the experience of self-

22 endorsement of one's activity), competence (the experience of effective involvement

23 in an activity), and relatedness (the experience of a sense of connectedness and

24 mutual respects; Deci \& Ryan, 2000). According to SDT (Ryan \& Deci, 2000),

25 positive environmental factors (e.g., parental support and quality coaching 
1 programmes) are nutriments for nurturing athletes’ basic psychological needs or

2 needs satisfaction. For example, the characteristics of long-term development focus

3 are to provide long-term development opportunities, avoid selection pressure, allow

4 making mistakes, and de-emphasize winning (Li et al., 2015). Under this

5 environment, athletes' autonomy and competence are believed to be fulfilled as they

6 are given opportunities to participate in their sports, have their own control on

7 selection pressure, and are able to understand winning or losing is not that important

8 during the early stage of development (Deci \& Ryan, 2000). Similarly, the other four

9 talent development environmental factor focus on providing high-quality training

10 programmes, offering personnel support, providing feedback and rationale for

11 training, and establishing reasonable goals (Li et al., 2015), and they are also likely

12 to enhance athletes' needs satisfaction (Deci \& Ryan, 2000). Therefore, it is highly

13 possible that the talent development environmental factors are relevant social

14 antecedents that can provide nutriments to satisfy athletes' three basic psychological

15 needs.

\section{Basic psychological needs and burnout}

17 There are several studies investigating the relationships between the three basic

18 psychological needs and athlete burnout (e.g., Hodge, Lonsdale, \& Ng, 2008;

19 Martinent, Decret, Guillet-Descas, \& Isoard-Gautheur, 2014). Earlier study findings

20 generally supported the negative relationships between the three basic psychological

21 needs and athlete burnout (e.g., Hodge et al., 2008; Martinent et al., 2014). A recent

22 meta-analytic research showed that needs satisfaction had a moderate to high

23 association with burnout ( $\mathrm{Li}$ et al., 2013). These findings are in line with the tenets

24 of SDT that unfulfilled basic psychological needs will lead to maladaptive

25 motivational outcomes such as burnout. SDT also maintains that positive social 
1 factors will enhance needs satisfaction and lead to positive personal growth such as

2 enhanced sports performance, whereas failure to provide supportive environments to

3 satisfy the basic psychological needs will result in physical and psychological ill-

4 being such as burnout (Deci \& Ryan, 2000).

\section{Environment, basic psychological needs, and burnout}

6 Burnout has received increasing attention in the sport literature (Goodger, Gorely,

7 Lavallee, \& Harwood, 2007). A close examination on social environment is

8 recommended to find out significant factors that potentially contribute to athlete

9 burnout (Curran, Appleton, Hill, \& Hall, 2011). Several significant factors such as

10 coaching climate (e.g., Isoard-Gautheur, Guillet-Descas, \& Duda, 2013; Lemyre,

11 Hall, \& Roberts, 2008), teammate support (e.g., DeFreese \& Smith, 2013; Smith,

12 Gustafsson, \& Hassmén, 2010), and parenting style (e.g., Gustafsson, Hill, Stenling,

13 \& Wagnsson, 2015) were found to be associated with burnout. Conceptually, these

14 identified factors are similar to (but distinct from) the five talent developmental

15 factors such as support network. To date, it is still unclear on how athlete burnout is

16 related to the five talent development environmental factors.

17 To explain the relations among environmental factors, needs satisfaction, and

18 motivational consequences (e.g., burnout), the model of motivation sequence was

19 developed by Vallerand (1997). In Vallerand's model, needs satisfaction is proposed

20 to mediate the effects of social factors on motivational consequences (i.e., social

21 factors $\rightarrow$ needs satisfaction $\rightarrow$ motivational consequences). The model of

22 motivational sequence has been examined in the sport literature (e.g., Alvarez,

23 Balaguer, Castillo, \& Duda, 2012; Jõesaar, Hein, \& Hagger, 2011). While the talent

24 development environment is of importance for developing athletes, its relationship 
1 with the development of the three basic psychological needs and prevention of

2 athlete burnout has not been examined via this model.

Past studies have shown that contextual factors exerted indirect effects on

4 motivational consequences via needs satisfaction (e.g., Alvarez et al., 2012; Sarrazin,

5 Vallerand, Guillet, Pelletier, \& Cury, 2002). Because examining the mediating

6 effects is meaningful for theoretical building of the psychological process (Preacher

7 \& Hayes, 2008), it is important to investigate how the talent development

8 environmental factors predict burnout via needs satisfaction.

\section{The current study}

10 To bridge the aforementioned literature gaps, this research was to investigate

11 the relationships among the talent development environment, needs satisfaction, and

12 burnout. Specifically, we intended to test the proposed mediation model (i.e., talent

13 development environment $\rightarrow$ needs satisfaction $\rightarrow$ burnout). According to the above

14 literature review, the following hypotheses were proposed: (a) the five talent

15 development environmental factors are potential predictors of needs satisfaction

16 (Hypothesis 1), (b) needs satisfaction is negatively related to burnout (Hypothesis 2),

17 and (c) needs satisfaction fully mediates the relationship between the talent

18 development environment and burnout (Hypothesis 3).

\section{Method}

\section{Participants}

21 Participants of this study must be youth talented athletes (13-18 years old) and were

22 involved in the talent development programmes at the time of data collection. A

23 sample of 691 talented young athletes (male $=343$, female $=348 ; M_{\text {age }}=14.11$,

$24 S D_{\text {age }}=1.04$ ) was recruited from the talent development programmes in Singapore.

25 There are different organisations available to offer talent development programmes 
1 in Singapore. The Youth Sports Academy and some national sports associations are

2 responsible for selecting and developing youth athletes who are studying in

3 mainstream schools. The Singapore Sports School is an independent specialised

4 school to identify and develop student-athletes guided by long-term development

5 principles. Athletes enrolling in the above organisations do receive high-quality

6 training and supporting programmes. Other than the aforementioned organisations, a

7 few mainstream schools are also running their own talent development programmes

8 (Li et al., 2015).

$9 \quad$ The participants were involved in 25 individual and team sports such as

10 basketball, golf, judo, netball, shooting, tennis, and track and field. On average, they

11 were involved in training for 4.76 years and 10.64 hours every week. The majority of

12 the respondents had competition experiences either at international ( $n=198 ; 29 \%)$

13 or national level ( $n=374,54 \%)$. Only a small number of participants competed at

14 zonal or inter-school level $(n=45 ; 6 \%)$ and the rest participants $(n=74 ; 11 \%)$ did

15 not indicate their highest competition level.

\section{Measures}

17 The battery of questionnaires measuring the talent development environmental

18 factors, needs satisfaction, burnout, and demographic information (e.g., gender, age,

19 and sports) were used. The reliability and validity of the scales are reported in the

20 results section.

\section{Talent Development Environment Questionnaire-5 (TDEQ-5)}

22 The 25-item TDEQ-5 (Li et al., 2015) was used to measure the key environmental

23 factors. The scale consisted of five factors: long-term development focus (five items;

24 e.g., "My coach allows me to learn through making my own mistakes”), holistic

25 quality preparation (seven items; e.g., "My coach rarely talks to me about my well- 
1 being”), support network (four items; e.g., "I can pop in to see my coach or other

2 support staff whenever I need to”), communication (four items; e.g., “My coach and

3 I often try to identify what my next big test will be before it happens”), and

4 alignment of expectations (five items; e.g., "My coaches make time to talk to my

5 parents about me and what I am trying to achieve”). Reliability and validity of the

6 TDEQ-5 was supported with the talented youth athletes from Singapore (Li et al.,

7 2015). A 6-point Likert scale ( 1 = "strongly disagree” and 6 = "strongly agree”) was

8 used for responses.

$9 \quad$ Basic Needs Satisfaction in Sport Scale (BNSSS)

10 Athletes' three basic psychological needs in sport were measured with the 15-item

11 BNSSS (Ng, Lonsdale, \& Hodge, 2011). Exemplar questions for each factor were: (a)

12 autonomy ("In my sport, I get opportunities to make choices”), (b) competence ("I

13 can overcome challenges in my sport”), and (c) relatedness (“In my sport, I feel close

14 to other people”). Each factor comprised five items. Reliability and validity of the

15 BNSSS were supported (Ng et al., 2011). For measuring item responses, a 7-point

16 Likert scale (1 = "not true at all”; 7 = "very true”) was employed. A composite score

17 of the three subscales (i.e., needs satisfaction) was calculated for further analyses.

18 Athlete Burnout Questionnaire (ABQ)

19 To measure athlete burnout, the ABQ was used (Raedeke \& Smith, 2001). The ABQ

20 assessed three burnout symptoms, namely reduced sense of accomplishment (e.g.,

21 “I’m not achieving much in sport”), emotional and physical exhaustion (e.g., "the

22 effort I spent in sport would be better spend doing other things”), and sport

23 devaluation (e.g., “I feel overly tired from my sport participation”). Each factor

24 consisted of five items. The construct validity and reliability of the ABQ has been

25 widely supported (e.g., Lonsdale \& Hodge, 2011; Raedeke \& Smith, 2001). Athletes 
1 were asked to respond to the degree of burnout experience over the last one month

2 through a 5-point Likert scale (1 = “almost never”, 5 = “almost always”).

\section{Procedures}

4 Ethical approval from the principal investigator's institution was obtained. Informed

5 written consents from participants and their parents/guardians to participate in the

6 study were obtained before conducting the survey. The researchers administered the

7 survey forms to the participants in quiet classrooms and supervised the procedure of

8 data collection. Participants were encouraged to respond to the surveys honestly and

9 informed that there were no correct or wrong answers for the survey. They were also

10 told that they could withdraw from this study at any time without penalty, prejudice,

11 negative consequences, or disadvantage. The survey took participants approximately

1220 minutes to complete.

\section{Data analyses}

14 In the preliminary analyses, missing data analysis, univariate and multivariate outlier

15 cleaning, and univariate normality test were conducted using SPSS 20.0 (see

16 Tabachnick \& Fidell, 2013). Next, descriptive statistics, internal reliability, and

17 inter-factor correlations of the major variables were computed.

18 To test the hypothesized model depicted in Figure 1, the two-step approach

19 of structural equation modeling (Anderson \& Gerbing, 1988) was adopted with

20 maximum likelihood estimator in AMOS 21.0 (Arbuckle, 2013). The first step is to

21 find an acceptable measurement model. Parcels were used for testing the model (see

22 Little, Cuningham, Shahar, \& Widaman, 2002). Each latent construct had three

23 parcels. For the TDEQ-5, either one, two, or three items from the corresponding

24 factors were randomly selected to form each parcel by averaging their scores. Three

25 parcels for the BNSSS were created according to the three measured facets (i.e., 
1 autonomy, competence, and relatedness). Each of the ABQ factors was indexed by

2 three parcels, and each parcel had one or two items that were randomly selected and

3 averaged from the corresponding factor. In total, 27 parcels (three parcels per each of

4 the nine factors) were created as indicators in assessing overall measurement model

5 fit. Building upon the acceptable measurement model, the second step is to evaluate

6 the fit of the hypothesized model (Brown, 2006).

$7 \quad$ Multiple fit indices were used as to assess model fit. A value of $\chi^{2} / d f$ smaller

8 than 3.0 indicates good model fit to the data (Kline, 2005). Values for Comparative

9 Fit Index $(\mathrm{CFI}) \geq .90$, Root Mean Square Error of Approximation $(\mathrm{RMSEA}) \leq .08$,

10 and Standardised Root Mean Square Residual (SRMR) $\leq .08$ represent a close model

11 fit (Hu \& Bentler, 1999; Marsh, Hau, \& Wen, 2004). Values for CFI $\geq$.95, RMSEA

$12 \leq .06$, and SRMR $\leq .08$ were used as evidence of good fit (Hu \& Bentler, 1999;

13 Marsh et al., 2004). Finally, to test the mediation effects, bias-corrected

14 bootstrapping methods with 5000 samples were applied (Preacher \& Hayes, 2008).

Results

\section{Preliminary analyses}

17 Expectation-Maximization algorithm was used for data imputation given that the

18 missing values were very small (i.e., less than 2.0\%; Hair, Black, Babin, \& Anderson,

19 2010). There were no outliers in the data set as all standardised items scores were

20 within the normal range between -3.29 and +3.29 . No multivariable outliers were

21 identified based on the results of Mahalanobis' distance. Further, all items were

22 univariate normally distributed (skewness $=-1.10$ to 1.49 , kurtosis $=-1.15$ to 1.53 ).

23 Table 1 shows the descriptive statistic of the observed variables. Participants

24 reported moderate (holistic quality preparation, support network, communication,

25 and alignment of expectations) to high (long-term development focus) scores of the 
1 talent development environmental factors and needs satisfaction, as well as moderate

2 scores of burnout. The used scales had acceptable to good internal reliability ( $\alpha=.76$

3 to .91). The five talent development environmental factors were positively correlated

4 with the three basic psychological needs and needs satisfaction (.15 to .51, $p s<.01$ ).

5 The three basic psychological needs and needs satisfaction were negatively

6 connected with overall burnout and its three factors (-.60 to -.16, ps $<.01)$.

****Table 1 near here ${ }^{* * * *}$

\section{Structural equational modeling}

11 Estimation of the measurement model yielded good model fit to the data, $\chi^{2}(288)=$

$12779.61, \chi^{2} / d f=2.78, \mathrm{CFI}=.952, \mathrm{SRMR}=.041, \mathrm{RMSEA}=.050,90 \% \mathrm{CI}$

13 (.046, .054). Table 1 presents the results of construct reliability and latent factor

14 correlations. Construct reliability of all factors were supported (.79 to .89). Latent

15 factor correlations ranged between -.45 to .82, supporting the discriminant validity

16 among the factors. These results supported the specified overall measurement model.

17 Building upon the valid measurement model, the analysis of the hypothesized

18 structural model yielded adequate model fit to the data, $\chi^{2}(303)=878.29, \chi^{2} / d f=$

$192.90, \mathrm{CFI}=.943, \mathrm{SRMR}=.058, \mathrm{RMSEA}=.052,90 \%$ CI $(.048, .057)$. Figure 1

20 shows the standardised estimates of the model. Long-term development focus ( $\beta$

$21=.28, p<.01)$, holistic quality preparation $(\beta=.15, p<.01)$, and communication $(\beta$

$22=.22, p=.02$ ) were significant predictors of needs satisfaction. The path estimates

23 between support network/alignment of expectations and needs satisfaction were not

24 significant $(\beta=.06 / .11, p=.42 / .24)$. Thus, Hypothesis 1 was partially supported. In

25 line with SDT and Hypothesis 2, needs satisfaction was negatively related to the 
1 three burnout factors $(\beta=-.70$ to $-.35, p s<.01)$. The talent development

2 environmental factors explained $44 \%$ variance for needs satisfaction. The talent

3 development environmental factors and needs satisfaction accounted for $48 \%, 12 \%$,

$422 \%$ of the variance in reduced sense of accomplishment, emotional and physical

5 exhaustion, and sport devaluation, respectively.

6 The additional investigation on the moderating effects of gender on the

7 hypothesized model was also conducted in this study. The results showed no gender

8 differences (detailed results are available from the first author upon request). The

9 moderating effect of age group on the model was not examined due to the small age

10 range of our participants (i.e., 13 to 18 years).

\section{Mediation analyses}

15 Table 2 lists the results of mediation analyses with bootstrapping. There were no

16 direct effects from the five talent development environmental factors on the three

17 burnout factors. Three out of the five tested mediation paths (indirect effect) were

18 significant at either .01 or .05 level. Needs satisfaction was a full mediator for the

19 relationships between long-term development focus/holistic quality

20 preparation/communication and the three burnout factors (see Table 2). These results

21 supported Hypothesis 3. 
1 Extending the literature, this survey study investigated the relationships among

2 athletes' perceptions of the five talent development environmental factors, needs

3 satisfaction, and burnout. The descriptive statistics showed a relatively high score on

4 long-term development focus $(M=4.78$, out of 6.00) as well as moderate scores on

5 holistic quality preparation, support network, communication, and alignment of

6 expectations $(M=3.81$ to 4.35 , out of 6.00$)$. It seems that the message of long-term

7 athletic development has been fairly adopted in the local talent development

8 programmes, and a higher quality of talent development environment may be

9 reinforced by improving the other four environmental factors.

10 Three hypotheses were formulated to test the proposed model predicting the

11 relationships among the talent development environmental factors, needs satisfaction

12 and burnout. The structural model showed adequate fit to the data, and Hypothesis 1

13 was partially supported. The paths between the three environmental factors (i.e.,

14 long-term development focus, holistic quality preparation, and communication) and

15 needs satisfaction were significant. According to the literature (Martindale et al.,

16 2010), the characteristics of these three environmental factors focus on de-

17 emphasizing on winning, offering high quality training programmes, and providing

18 timely feedback and reviews on the talent development programmes. In other words,

19 athletes who are trained in effective talent development environments are given

20 choices in decision making, provided with meaningful rationale for long-term

21 athletic development, and endowed with development of competence through

22 holistic training programmes. Hence, athletes' autonomy and competence are built

23 through these three effective environmental factors.

24 Unexpectedly, however, support network (mainly concerning sport scientists’

25 professional support to athletes) failed to predict needs satisfaction in the structural 
1 model and the strength for the path estimate was negligible $(\beta=.06)$. This finding

2 can be due to the nature of the local social setting. In Singapore, very few sports

3 teams have full time sport scientists and athletes are not able to see them on a daily

4 basis. Therefore, sport scientists are unlikely to build close relationships with

5 athletes. Participants' relatedness may not be satisfied through the sport science

6 support (Deci \& Ryan, 2000). The item contents in support network of the TDEQ-5

7 may also contribute to the non-significant path. It is expected that athletes could feel

8 more connected with and valued by family members rather than sport scientists. A

9 recent study showed that both parental and coach support were associated with

10 athletes' needs satisfaction, and the effect was greater within the parental relational

11 context than within the coaching one (Felton \& Jowett; 2013). Most of the items in

12 support network described sport science support rather than parental or coach

13 support so that support network had no significant association with athletes' needs

14 satisfaction. On the other hand, there may be a connection between support network

15 and needs satisfaction under other social contexts, where athletes had more contacts

16 with support staff.

17 While alignment of expectations was supposed to be an antecedent of needs

18 satisfaction in Hypothesis 1, the result showed a non-significant relationship ( $\beta$

$19=.11$ ). In the effective talent development environment, alignment of expectations

20 was characterized as adjusting goals for sport development while taking athletes' and

21 parents' perspectives ( $\mathrm{Li}$ et al., 2015). To this end, athletes are allowed to be

22 involved in setting reasonable goals, which subsequently enhance their autonomy

23 and competence. However, the items within alignment of expectations were not

24 specifically devised to assess athletes' perceptions of motivational climate or goal

25 orientation cues emphasised by their coaches and/or parents. Past research indicated 
1 that there were positive relationships between task-involving climates and needs

2 satisfaction (e.g., Balaguer et al., 2012; Duda \& Hall, 2001). On the contrary,

3 evidence showed that needs satisfaction had associations with task-involving

4 climates but no or weak relation to ego-involving climates (e.g., Balaguer et al., 2012;

5 Reinboth \& Duda, 2006). Therefore, it is deemed that the nature of the item wording

6 within alignment of expectations may contribute to the non-significant path.

The non-significant paths between support network/alignment of

8 expectations and needs satisfaction should not be interpreted as the two

9 environmental factors were not effective nor important for talent development.

10 Instead, the current findings provided evidence that the two environmental factors

11 measured by the TDEQ-5 were not motivational antecedents of needs satisfaction

12 under the theoretical framework of SDT. Although the SDT constructs accounted for

13 relatively large variance of athlete burnout, supporting its practical use in

14 understanding athlete burnout, it might not fully explain this psychological symptom.

15 Thus, it might be useful to incorporate other theoretical frameworks (e.g., cognitive-

16 affective model; Smith, 1986) with SDT to help researchers better understand athlete

17 burnout. For example, according to the cognitive-affective model (1986), burnout

18 was viewed as a response to stress. The five talent development environmental

19 factors are likely to be cognitively appraised as the aversive sources of stress when

20 athletes' needs satisfaction is enhanced within the talent development context (i.e.,

21 talent development environment $\rightarrow$ needs satisfaction $\rightarrow$ stress $\rightarrow$ burnout).

22 Meanwhile, the two environmental factors may become critical predictors under

23 other theoretical frameworks.

24 Hypothesis 2 was confirmed in the current study. Specifically, needs

25 satisfaction was negatively related to the three burnout factors, which is consistent 
1 with the previous meta-analytic results (Li et al., 2013) and SDT (Deci \& Ryan,

2 2000). In line with Hypothesis 3, the results of the mediation analyses indicated that

3 the relationships between the three environmental factors (i.e., long-term

4 development focus, holistic quality preparation, and communication) and the three

5 burnout factors were full mediated by needs satisfaction. These findings provide

6 initial evidence of the underlying mechanism for the effects of the three

7 environmental factors on athlete burnout via needs satisfaction. In addition, the three

8 talent development environmental factors together with needs satisfaction account

9 for a moderate to large variance in the three burnout factors (12\% to 48\%; Cohen,

10 1988). The large explained variance implies that the talent development

11 environmental factors are important correlates of burnout within the lens of SDT.

\section{Limitations and implications}

13 Several limitations and implications pertaining to the current research are

14 discussed in this section. First, the proposed research questions were examined using

15 cross-sectional quantitative approach so that the causal conclusions should be drawn

16 with caution. Alternatively, a longitudinal or experimental study can be used to test

17 the research questions. Second, it is suggested that needs thwarting should be

18 included and tested in the model given needs satisfaction and needs thwarting are

19 two different concepts (Bartholomew, Ntoumanis, Ryan, \& Thøgersen-Ntoumani,

20 2011; Vansteenkiste \& Ryan, 2013). Put simply, whereas low needs satisfaction will

21 result in functional costs over the time, the undermining process will be accelerated

22 when needs are thwarted. Finally, the findings from this research identified three key

23 environmental factors that can be used by practitioners who are involved with talent

24 development programmes to nurture needs satisfaction and avoid athlete burnout.

25 For example, coaches are encouraged to implement a long-term developmental 
1 programme (e.g., letting athletes understand the rationale of long-term development

2 and diluting the importance of winning), provide high-quality and holistic training

3 (e.g., giving a reasonable training load and showing cares to athletes), and open a

4 door for the coach-athlete communication (e.g., giving formative feedback and

5 making two-way communication easy). Parents should also encourage children when

6 they confront with problems, communicate with coaches about their children's

7 involvement in sports, and support their children's competitions.

\section{Conclusions}

9 Support network and alignment of expectations are not significant predictors of

10 needs satisfaction. The three talent development environmental factors (i.e., long-

11 term development focus, holistic quality preparation, and communication) positively

12 predict athletes' needs satisfaction. Moreover, SDT is identified as a useful

13 theoretical framework in conceptualizing the role of talent development environment

14 on needs satisfaction and understanding athlete burnout. The current research sheds

15 light on how to better prepare talented adolescent athletes to elite levels by

16 facilitating their needs satisfaction and preventing burnout through providing the

17 effective talent development environmental antecedents. 


\section{References}

2 Anderson, J. C., \& Gerbing, D. W. (1988). Structural equation modeling in practice: A review and recommended two-step approach. Psychological Bulletin, 103, 411-423.

5 Araújo, D., \& Davids, K. (2011). Talent development: From possessing gifts, to functional environmental interactions. Talent Development \& Excellence, 3, 23-25.

8 Arbuckle, J. L. (2013). IBM ${ }^{\circledR}$ SPSS ${ }^{\circledR}$ Amos $^{\mathrm{TM}} 22$ User’s Guide. Chicago, IL: IBM.

9 Baker, J., \& Schorer, J. (2010). Identification and development of talent in sport:

10 Introduction to the special issue. Talent Development \& Excellence, 2, 119121.

12 Balaguer, I., González, L., Fabra, P., Castillo, I., Mercé, J., \& Duda, J. L. (2012). Coaches’ interpersonal style, basic psychological needs and the well-and illbeing of young soccer players: A longitudinal analysis. Journal of Sports Sciences, 30, 1619-1629. doi: 10.1080/02640414.2012.731517

16 Bartholomew, K., Ntoumanis, N., Ryan, R. M., \& Thøgersen-Ntoumani, C. (2011). Psychological need thwarting in the sport context: Assessing the darker side of athletic experience. Journal of Sport and Exercise Psychology, 33, 75-102.

19 Brown, T. A. (2006). Confirmatory factor analysis for applied research. New York, 20 United States: The Guilford Press.

21 Cohen, J. (1988). Statistical power analysis for the behavioral sciences. Hillsdale, NJ, United States: Lawrence Erlbaum Associates.

23 Collins, D., \& MacNamara, Á. (2012). The rocky road to the top. Sports Medicine, 42, 907-914. 
1 Curran, T., Appleton, P. R., Hill, A. P., \& Hall, H. K. (2011). Passion and burnout in elite junior soccer players: The mediating role of self-determined motivation. Psychology of Sport and Exercise, 12, 655-661. doi:10.1016/j.psychsport.2011.06.004

5 Deci, E. L., \& Ryan, R. M. (2000). The "what” and "why” of goal pursuits: Human needs and the self-determination of behavior. Psychological Inquiry, 11, 227268. doi:10.1207/S15327965PLI1104_01

DeFreese, J. D., \& Smith, A. L. (2013). Teammate social support, burnout, and selfdetermined motivation in collegiate athletes. Psychology of Sport and Exercise, 14, 258-265. doi:10.1016/j.psychsport.2012.10.009

Duda, J. L., \& Hall, H. K. (2001). Achievement goal theory in sport: Recent extensions and future directions. In R. N. Singer, H. A. Hausenblas, \& C.M. Janelle (Eds.), Handbook of research in sport psychology (2nd ed., pp. 417434). New York, United States: John Wiley and Sons, Inc.

Ericsson, K. A. (2007). Deliberate practice and the modifiability of body and mind: Toward a science of the structure and acquisition of expert and elite performance. International Journal of Sport Psychology, 38, 4-34.

Felton, L., \& Jowett, S. (2013). Attachment and well-being: The mediating effects of psychological needs satisfaction within the coach-athlete and parent-athlete relational contexts. Psychology of Sport and Exercise, 14, 57-65.

22 Goodger, K., Gorely, T., Lavallee, D., \& Harwood, C. (2007). Burnout in sport: A systematic review. Sport Psychologist, 21, 125-151.

24 Gustafsson, H., Hancock, D. J., \& Côté, J. (2014). Describing citation structures in 25 sport burnout literature: A citation network analysis. Psychology of Sport and 
Exercise, 15, 620-626. doi:10.1016/j.psychsport.2014.07.001

Gustafsson, H., Hassmén, P., Kenttä, G., \& Johansson, M. (2008). A qualitative analysis of burnout in elite Swedish athletes. Psychology of Sport and Exercise, 9, 800-816. doi:10.1016/j.psychsport.2007.11.004

Gustafsson, H., Hill, A. P., Stenling, A., \& Wagnsson, S. (2015). Profiles of perfectionism, parental climate, and burnout among competitive junior athletes. Scandinavian Journal of Medicine \& Science in Sports. doi: 10.1111/sms.12553

Gustafsson, H., Kenttä, G., \& Hassmén, P. (2011). Athlete burnout: An integrated model and future research directions. International Review of Sport and Exercise Psychology, 4, 3-24. doi:10.1080/1750984x.2010.541927

Hair, J. F., Black, W. C., Babin, B. J., \& Anderson, R. E. (2010). Multivariate data analysis (7th ed.). NJ, United States: Pearson Prentice Hall.

Henriksen, K., Larsen, C. H., \& Christensen, M. K. (2014). Looking at success from its opposite pole: The case of a talent development golf environment in Denmark. International Journal of Sport and Exercise Psychology, 12, 134149. doi: 10.1080/1612197X.2013.853473

Henriksen, K., Stambulova, N., \& Roessler, K. K. (2010). Holistic approach to athletic talent development environments: A successful sailing milieu. Psychology of Sport \& Exercise, 11, 212-222. doi:10.1016/j.psychsport.2009.10.005

Hodge, K., Lonsdale, C., \& Ng, J. Y. Y. (2008). Burnout in elite rugby: relationships with basic psychological needs fulfilment. Journal of Sports Sciences, 26, 835-844. doi:10.1080/02640410701784525. 
1 Hu, L., \& Bentler, P. M. (1999). Cutoff criteria for fit indexes in covariance structure analysis: Conventional criteria versus new alternatives. Structural Equation Modeling: A Multidisciplinary Journal, 6, 1-55 doi:10.1080/10705519909540118

5 Isoard-Gautheur, S., Guillet-Descas, E., \& Duda, J. L. (2013). How to achieve in elite training centers without burning out? An achievement goal theory perspective. Psychology of Sport and Exercise, 14, 72-83. doi:10.1016/j.psychsport.2012.08.001

9 Jõesaar, H., Hein, V., \& Hagger, M. S. (2011). Peer influence on young athletes’ need satisfaction, intrinsic motivation and persistence in sport: A 12-month

13 Kline, R. B. (2005). Principles and practice of structural equation modeling (2nd ed.). New York, NY, United States: The Guilford Press.

15 Lemyre, P. N., Hall, H. K., \& Roberts, G. C. (2008). A social cognitive approach to burnout in elite athletes. Scandinavian Journal of Medicine \& Science in Sports, 18, 221-234. doi:10.1111/j.1600-0838.2007.00671.x

18 Li, C., Wang, C. J., \& Pyun, D. Y. (2014). Talent development environmental factors in sport: A review and taxonomic classification. Quest, 66, 433-447. doi:10.1080/00336297.2014.944715

21 Li, C., Wang, C. J., Pyun, D. Y., \& Kee, Y. H. (2013). Burnout and its relations with basic psychological needs and motivation among athletes: A systematic review and meta-analysis. Psychology of Sport and Exercise, 14, 692-700. doi:10.1016/j.psychsport.2013.04.009

25 Li, C., Wang, C. K. J., Pyun, D. Y., \& Martindale, R. (2015). Further development 
of the Talent Development Environment Questionnaire for sport. Journal of Sports Sciences, 33, 1831-1843. doi:10.1080/02640414.2015.1014828

Little, T. D., Cunningham, W. A., Shahar, G., \& Widaman, K. F. (2002). To parcel or not to parcel: Exploring the question, weighing the merits. Structural Equation Modeling, 9, 151-173. doi: 10.1207/S15328007SEM0902_1

Lonsdale, C., \& Hodge, K. (2011). Temporal ordering of motivational quality and athlete burnout in elite sport. Medicine \& Science in Sports \& Exercise, 43, 913-921. doi:10.1249/MSS.0b013e3181ff56c6

Marsh, H.W., Hau, K-T. \& Wen, Z. (2004). In search of golden rules: Comment on hypothesis-testing approaches to setting cutoff values for fit indexes and dangers in overgeneralizing Hu and Bentler’s (1999) findings. Structural Equation Modeling: A Multidisciplinary Journal, 11, 320-341.

Martindale, R. J. J., Collins, D., \& Daubney, J. (2005). Talent development: A guide for practice and research within sport. Quest, 57, 353-375.

Martindale, R. J. J., Collins, D., Wang, C. K. J., McNeill, M., Lee, K. S., Sproule, J., \& Westbury, T. (2010). Development of the talent development environment questionnaire for sport. Journal of Sports Sciences, 28, 1209-1221. doi:10.1080/02640414.2010.495993

Martinent, G., Decret, J. C., Guillet-Descas, E., \& Isoard-Gautheur, S. (2014). A reciprocal effects model of the temporal ordering of motivation and burnout among youth table tennis players in intensive training settings. Journal of Sports Sciences, 32, 1648-1658.doi:10.1080/02640414.2014.912757

Ng, J. Y. Y., Lonsdale, C., \& Hodge, K. (2011). The Basic Needs Satisfaction in Sport Scale (BNSSS): Instrument development and initial validity evidence. 
Psychology of Sport and Exercise 12, 257-264. doi:10.1016/j.psychsport.2010.10.006

3 Phillips, E., Davids, K., Renshaw, I., \& Portus, M. (2010). Expert performance in sport and the dynamics of talent development. Sports Medicine, 40, 271-283.

5 Preacher, K. J., \& Hayes, A. F. (2008). Asymptotic and resampling strategies for assessing and comparing indirect effects in multiple mediator models. Behavior Research Methods, 40, 879-891. doi:10.3758/BRM.40.3.879

8 Raedeke, T. D. (1997). Is athlete burnout more than just stress? A sport commtment perspective. Journal of Sport \& Exercise Psychology, 19, 396-417.

10 Raedeke, T. D., \& Smith, A. L. (2001). Development and preliminary validation of an athlete burnout measure. Journal of Sport \& Exercise Psychology, 23, 281-306.

13 Reinboth, M., \& Duda, J. L. (2006). Perceived motivational climate, need satisfaction and indices of well-being in team sports: A longitudinal

17 Sarrazin, P., Vallerand, R., Guillet, E., Pelletier, L., \& Cury, F. (2002). Motivation and dropout in female handballers: A 21-month prospective study. European Journal of Social Psychology, 32, 395-418. doi:10.1002/ejsp.98

20 Ryan, R. M., \& Deci, E. L. (2000). Intrinsic and extrinsic motivations: Classic definitions and new directions. Contemporary Educational Psychology, 25, 54-67. doi:10.1006/ceps.1999.1020

23 Schaufeli, W. B., \& Buunk, B. P. (2003). Burnout: An overview of 25 years of 24 research and theorizing. In M. J. Schabracq, J. A. M. Winnubst \& C. L. 
Cooper (Eds.), The handbook of work and health psychology (2nd ed., pp. 383-425). New York, NY, United States: John Wiley \& Sons.

3 Smith, R. E. (1986). Toward a cognitive-affective model of athlete burnout. Journal of Sport Psychology, 8, 36-51.

5 Smith, A. L., Gustafsson, H., \& Hassmén, P. (2010). Peer motivational climate and burnout perceptions of adolescent athletes. Psychology of Sport and Exercise, 11, 453-460. doi:10.1016/j.psychsport.2010.05.007

8 Tabachnick, B. G., \& Fidell, L. S. (2013). Using multivariate statistics (6th ed.). Boston, United States: Allyn Bacon.

10 Vallerand, R. J. (1997). Toward a hierarchical model of intrinsic and extrinsic motivation. In M. P. Zanna (Ed.), Advances in experimental social psychology (pp. 271-360). New York, NY, United States: Academic Press.

13 Vansteenkiste, M., \& Ryan, R. M. (2013). On psychological growth and vulnerability: Basic psychological need satisfaction and need frustration as a unifying principle. Journal of Psychotherapy Integration, 23, 263-280.

17 Williams, A. M., \& Reilly, T. (2000). Talent identification and development in soccer. Journal of Sports Sciences, 18, 657-667. 